\title{
LEGISLATION AND PNEUMOCONIOSIS
}

\author{
By Chas. L. Sutherland, M.D., D.P.H., D.I.H. \\ Senior Medical Officer, Ministry of National Insurance
}

\section{Historical}

Now that the Workmen's Compensation Acts have been replaced by the National Insurance (Industrial Injuries) Act, 1946, interest in them is rapidly becoming an academic matter. A review of the extension of workmen's compensation to sufferers from industrial pulmonary diseases due to dusts, over the past 40 or 50 years, provides however a good background to a study of the subject of pneumoconiosis. No step in legislation has been taken in advance of medical knowledge of the subject. If progress has been slow, the basis for each advance has been correspondingly sure.

The Workmen's Compensation Act, 1906, made provision for the first time for the payment of compensation to workmen contracting an occupational disease. Only a few specified diseases were included but the Act gave power to the Secretary of State to bring other diseases under the Act. The inclusion of fibroid phthisis was considered by a Committee on Compensation for Industrial Diseases (1907) set up before the Act came into force. It was found that fibroid phthisis was a trade disease affecting ganister miners, silica brickmakers, metal grinders, certain pottery workers and granite and gritstone masons. The Committee, however, did not recommend the addition of the disease to the Schedule to the Act, one of the reasons given being that of the difficulty of diagnosis, especially in the early stage. A way to overcome this was opened by Summons (I907) who advocated the use of the X-ray in diagnosis. At that date radiography was in a very primitive state and even as late as 1914 its use in this connection was not appreciated or mentioned in the Second Report of the Royal Commission on Metalliferous Mines and Quarries. In South Africa greater progress had been made for in I916 the Miners Phthisis Prevention Committee made use of the words which have become one of the axioms of the subject :- ' the radiographic appearances in cases of silicosis affords the most reliable single piece of evidence in establishing the existence and the actual stage of the disease in any particular case.'

The Royal Commission referred to, pointed out the value of post-mortem examination as providing evidence as to the presence of the disease and this led later to special provisions as to post- $\frac{\widehat{\Phi}}{\alpha}$ mortems in Compensation Schemes and to the addition of industrial fibroid phthisis to the causes ${ }^{\infty}$ of death of cases to be reported by Registrars of deaths to Coroners. To this is due the great con- $\overrightarrow{\vec{\omega}}$ tribution pathology has since made to the advance $\omega$ of knowledge of the subject in this country.

Professor E. L. Collis' Milroy Lectures (1915) marked the arrival at a stage when emphasis was in placed on silica $\left(\mathrm{SiO}_{2}\right)$ as the causal agent of dust $\mathrm{i}$ disease, and paved the way for a real start in $\bigcirc$ compensation legislation. As a result of pressure by workers in ganister mining and the allied trade $O$ of silica brickmaking, the Workmen's Compensa tion Act of 1918 was passed giving the Secretaojof State power to make schemes for the payme

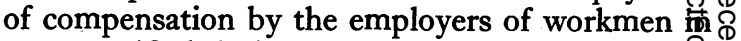
any specified industry or process or group processes involving exposure to silica dust.

\section{Refractories Industries}

There was only one scheme issued under tion 1918 Act and this was naturally enough the Refractories Industries (Silicosis) Scheme, I919. This provided for payment of compensation to ganister miners and silica brickmakers, who $\frac{\varrho}{\varnothing}$ suffered death, or were totally disabled, or who were found to be suffering from silicosis or silicosis $\overrightarrow{\vec{O}}$ accompanied by tuberculosis to such a degree as to make it dangerous to continue in the industry and for that reason were suspended from employment. This Act and Scheme had several serious defects, and these were studied by a Departmental:Committee whose report was issued in 1924. One $\frac{3}{3}$ was that payment of compensation in cases of silicosis accompanied by tuberculosis was limited $\mathrm{O}$ to cases in which the silicosis was so far advanced as to make the workmen specially liable to tuber- $\frac{3}{2}$ culosis or though not so far advanced was likely $\frac{D}{O}$ to accelerate materially the progress of the disease. Those who had to work the scheme by carrying out $N_{\sigma}$ the examinations protested against this, urging that it was not practical to make such an estimation of ${ }^{\circ}$ the stage of the silicosis or alternatively that they ${ }^{\omega}$ did not know what the words meant. This objection was met in the Workmen's Compensation (Silicosis) Act, 1924, when silicosis accompanied by tuberculosis was placed on the same footing? 
as silicosis alone, and in all further extensions of compensation the same rule has been followed, and it has been carried on in the present legislation. In passing it may be mentioned that although there is good reason to believe that there is a very close association of silicotic fibrosis and the development of tuberculosis in silicosis cases, the evidence is much less strong in other dust exposures such as asbestos. It is important to remember this especially now where claims in respect of pneumoconiosis may be made under the present legislation by tuberculous cases in occupations where dust exposure is slight or of doubtful quality. The need for weighing carefully the details of the industrial history is apparent.

Another defect of this first Refractories Industries Scheme was that no provision was made for the removal from the occupation of workers with tuberculosis without silicosis. Power was, however, given in the 1924 Act to deal with this source of infection.

The 'Refractories Industries' constitute a very small industry employing about 3,000 men mostly in the Sheffield district, South Wales, Durham and mid-Scotland. The final product is a silica brick, or silica cement for use in steel furnaces or gas retorts. To distinguish the silica brick industry from the fireclay industry, the material worked has to contain not less than 80 per cent. of total silica $\left(\mathrm{SiO}_{2}\right)$. A percentage introduced in this way gave rise to the idea that this represented a limit of safety ; this is, of course, not so. The employers agreed to form a company to administer the financial side of the compensation scheme for the payment of compensation and to pay for the medical examinations including initial and periodical examinations. These examinations were at first carried out by the tuberculosis officers of the area but after 1925 a whole-time Silicosis Medical Board was set up to do the work.

\section{Metal Grinding}

The Workmen's Compensation (Silicosis) Act, 1924, which amended the 1918 Act, defined silicosis as fibrosis of the lungs due to silica dust, and contained the amendments already referred to. The first scheme issued under the Act was the Metal Grinding Industries (Silicosis) Scheme, 1927, which covered workers engaged in grinding metals with a grindstone and in certain processes in the preparation of the grindstone for use. From I8I9 when Dr. Arnold Knight read a paper to the Sheffield Medical Chirurgical Society on the subject, the mortality of Sheffield grinders had been well known and many efforts had been made to reduce the risk. The publication of a report by Macklin and Middleton (1923) on the results of an investigation made by the Home Office led to the replacement of the sandstone grindstone by the abrasive wheel composed of carborundum or alumina abrasive material. These wheels produced less dust than the grindstone and such dust as is produced is not known to be dangerous. The definition of grindstone as a grindstone composed of natural or manufactured sandstone still holds good today. It is to be noted that manufactured sandstone means a material made up from sand not from abrasive material such as carborundum or alumina. The Metal Grinding (Silicosis) Scheme, 1927, gave compensation to workers who were totally disabled by the disease.

\section{The Various Industries (Silicosis) Scheme, 1928}

A similar scheme, the Various Industries (Silicosis) Scheme, 1928, extended the provisions of the Act to a number of occupations and processes, but like the Metal Grinding Scheme, only covered cases where death was due to the disease or the worker was totally disabled. The following processes or occupations were involved :-The mining or quarrying of silica rock, and drilling and blasting in silica rock, brought in the hard o header (crutter, brusher, brancher, stoneman) iro coal mines, and the quarrying of sandstone foe building. (Masons on building sites were dealb with under the processes defined as sawing planing, dressing, shaping, cutting or carving of silica rock. An amendment later (February I93I) added the dressing of granite by masons for building, civil engineering or monumentat. purposes.) Tin mining and the manufacture of scouring powders were also covered.

\section{Sandstone Industry (Silicosis) Scheme, r929}

This scheme was issued because the employers quarrying sandstone for building purposes agreed to form a company as in the refractories industries with similar provisions for financial matters and examinations. The workmen employed on stone in quarries were examined initially and periodically by the medical board. The older and skilled workers were only suspended on a written request by the workman. The numbers employed in the sandstone industry at one time reached 8,000 . The sandstone industry and the granite masons were dealt with only after enquiries by the members of the silicosis boards had shown that there was a considerable risk in the processes and occupations.

\section{Pottery Processes}

As already stated a Committee on Compensation for Industrial Diseases in 1907 had advised that potters engaged in certain processes were liable to be the victims of a specific trade disease but the 
Committee found difficulty in scheduling this disease under the Workmen's Compensation Acts. About 1923 the matter was raised again, and as a result a special enquiry was made by Sutherland and Bryson (1926) as to the incidence of silicosis in the pottery industry. They found that the disease is specially liable to be produced in those workers exposed to unmixed flint dust, and that it occurs to a less extent among workers in occupations which expose them to the mixed dust of the composite body of the ware which contains flint. These conclusions were considered by some critics to be too sweeping and the whole subject was studied by a departmental committee in 1928 . As a result, a number of occupations were added to paragraph 2 of the Various Industries Scheme including the milling of flint, the manufacture of china or earthenware up to and including the preparation for glazing, and polishing and tile slabbing. The process in the manufacture of china included the dangerous process of bedding china in powdered flint for the biscuit firing and the scouring of the ware to free it from flint afterwards. The danger of this process has been abolished by the substitution of alumina for flint in 1937.

\section{Steel Fettling or Dressing}

This process under the description of ' freeing of steel castings from adherent sand or other siliceous substance,' was included in the Various Industries Scheme. It had been studied by Macklin and Middleton who, on the petrological examination of the dust, assumed that this exposure carried a hazard to the workers. Experience has shown that although the numbers are not great the type of disease found may be severe. The difference between steel and other castings lies in the fact that the scale on steel castings is much more adherent, requires greater effort to remove it by hand chisel or pneumatic tool and so gives rise to a greater amount of dangerous dust. Iron castings give rise to much less dust and non-ferrous castings to very little.

\section{Sandblasting of Metals}

This was also dealt with by Macklin and Middleton and was added to the list of occupations in the Various Industries Scheme, 1928. The wording ' sandblasting of metal or articles of metal by means of compressed air with the use of quartzose sand or crushed silica rock or flint,' excludes the sandblasting of glass, and also the use of shot in blasting. These were added as compensatable occupations at a much later date, in 1946. The occupation as originally defined was one of the most dangerous as the report by Merewether showed in 1936 . This led to notice being taken of the effect of sandblasting on glass and also to an appreciation of the fact that the shot in shotblasting dislodged a dangerous siliceous dust from the scale which was removed from the casting.

\section{Tin Mines}

The association of the tin mining industry in Cornwall with silicosis had been made the subject of a report by Haldane (1904). He showed that the introduction of machinery greatly increased the number of miners who developed the disease. The country rock which is encountered in reaching the tin is either a granite or killas, a slatey material, but it is probable that the most dangerous dust arises from the quartz in which the tin itself is embedded. Workers underground in tin mines and also working with the ore on the surface were included in the Various Industries Scheme.

The Various Industries (Silicosis) Scheme, 1931, added to those benefiting any workmen who 'though not totally disabled are suffering from silicosis or from silicosis accompanied by tuberculosis to such a degree as to make it dangeroud for them to continue work in the processes and for that reason were suspended from the employ? ment.'

At the same time a whole-time medical boar $\Phi$ was set up with panels of two medical officers in different centres. A special Medical Expense Fund was also set up to provide for the payment. of medical officers' salaries and office and other expenses under the schemes. This was laid down in detail in the Silicosis and Asbestosis (Medical Arrangements) Scheme, I93I, which came into force on June I, I93I.

The medical board, in addition to the periodical and initial examination under the Refractories Industries Scheme and Sandstone Scheme, carried out such examinations of workers in some of the dangerous pottery processes and also workers in asbestos processes.

\section{Asbestosis}

Following the description of cases of lung disease in asbestos workers by W. E. Cooke, 1924 ; Stuart McDonald, 1927 ; and H. E. Seiler, 1928 ; an enquiry was carried out on behalf of the Home Office by Merewether and Price (1930). The conclusions reached were that there is an occupational risk in the asbestos industry taking the form of a o type of fibrosis of the lungs, quite distinct from N silicosis. This was the first departure from the $\underset{\mathcal{N}}{N}$ idea that silica $\left(\mathrm{SiO}_{2}\right)$ was the only dangerous dust. Silica dust produces a very characteristic patho- 0 logical lesion and modern opinion associates this with a chemical action on the lungs due to the $\stackrel{0}{?}$ 
close application of the particles to the tissues. Asbestos dust produces a different pathological lesion associated with bronchitis and emphysema, and opinion is not so clear as to how it is caused. A special Act extended the powers of the Secretary of State to make a scheme to cover asbestosis (defined as fibrosis of the lungs due to asbestos dust) and a scheme followed on the lines of the Various Industries Scheme. Medical examinations were carried out by the silicosis medical board and in some processes periodical and initial examinations were required. Asbestosis accompanied by tuberculosis was to be treated as asbestosis.

\section{Coal Mining Industry}

Under the Various Industries Scheme, I928, only workers in coal mines were included who were "drilling and blasting in silica rock, in or incidental to the mining or quarrying of other minerals.' This was the work of Tattersall (1926), who showed that hardheaders who drilled the above in South Wales coal mines contracted silicosis. The number of coal miners who applied for examination under the scheme was much greater than expected and many failed in their applications because they were unable to prove that they had drilled silica rock. In 1930 this was amended and the scope of the scheme enlarged. The Various Industries Scheme, I93 I, by allowing claims from workers partially disabled as well as totally disabled brought a considerable increase in claims and many found difficulty in establishing legally their exposure to silica dust. As a result the scheme was amended on October 22, 1934, to include ' any operation underground in any coal mine' in addition to the other processes.

From the beginning a large proportion of the cases arose in South Wales, and in that coalfield the number of claims continued to rise. In 1936 Keating and Thomas showed members of the Industrial Pulmonary Diseases Committee of the Medical Research Council that the increase in claims was accompanied by an increase in refusals of certificates. The matter was one of diagnosis, and the standard of diagnosis adopted was that of the first stage of the classification laid down in the Report of the Departmental Committee for Silicosis in the Pottery Industry in 1928:-

' The first stage shall be defined as characterized by:-

(a) the appearance of the earliest detectable physical signs of the disease with

(b) radiographic appearances not less than the presence of nodular shadows together with an increase of the hilum shadows, linear shadows and pulmonary reticulation, and (c) with or without impairment of capacity for work.'

A similar view of the diagnosable stage was taken at the International Conference on Silicosis at Johannesburg in 1930.

Keating and Thomas considered that there was a type of pulmonary disease due to the occupation, which was disabling and which did not come within the radiographic definition of silicosis. They described the $\mathrm{X}$-ray appearance as a ' reticulation' and not a nodulation.

The Industrial Pulmonary Diseases Committee appointed P. D'Arcy Hart and E. A. Aslett to make an enquiry into this pulmonary abnormality in South Wales coal miners and T. Belt and A. A. Ferris wrote a report on the pathology and histology of the condition. The Committee found that, while hardheaders develop silicosis, miners at the coalface develop a condition for which the term silicosis could not really be applied owing alike to the type of dust exposure and the radiographical and pathological findings. The Committee adopted the term 'pneumoconiosis of coal workers ' to cover the disease in hardheaders and coalface workers and decided that the $\mathrm{X}$-ray standard for the diagnosis of pneumoconiosisp should include reticulation as well as nodulation and consolidation.

Reticulation is defined radiographically Hart and Aslett as :-

'Lung fields show a fine network, sometime sharp and lace-like in pattern, but much more often blurred in appearance. The network occupies from half of one lung field to (more frequently) the whole of both fields, though the apices are relatively free. It is as marked at the periphery of the fields as it is nearer the hila. Shadows to be described under the heading of nodulation, if present in addition, are limited to one rib space. (Films with homogeneous or patchy shadows at one or both apices, but with reticulation elsewhere, are included in the reticulation category.) '

The pathological description by Belt and Ferris includes the definition:-'Dust reticulation; a dust-ridden state of the lungs corresponding to $\mathrm{X}$-ray reticulation, characterized by accumulation of silica and concomitant elaboration of reticular tissue throughout the framework of the lungs.'

Although the term 'dust reticulation' is retained the remainder of the definition is not completely accepted. The Report of the Advisory Committee on the Treatment and Rehabilitaion of Miners in the Wales Region suffering from Pneumoconiosis, published in 1944, considered that since trimmers at docks and screen workers at collieries developed pneumoconiosis it was not necessary to stipulate the presence of silica as

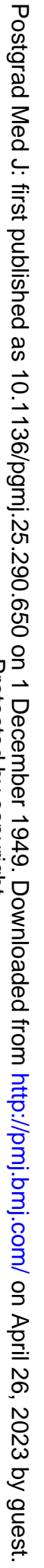


distinct from coal in the causation of the disease. This report also cites Enid Williams and Professor Gough in their description of the coal nodule with its accompanying focal emphysema as the essential lesion in coalface workers and trimmers and this is the view now generally held.

As a result of the Medical Research Council's report in 1942, the Workmen's Compensation Act, 1943, was passed to provide for the making of schemes applying the Workmen's Compensation Act to workmen suffering from any form of pneumoconiosis and in this Act the expression pneumoconiosis means:- 'Fibrosis of the lungs due to silica dust, asbestos dust, or other dust and includes the condition of the lung known as dust reticulation.'

The word ' fibrosis' suggests to most of us a collageous fibrosis and such fibrosis is not present in most cases of reticulation. Whether reticular tissues as demonstrated by Belt constitute a fibrosis or not has been questioned, but reticulin 'fibrosis' is a common tissue reaction to injury, infection and foreign bodies and it is not a specific process limited to the lung (Gough, 1948).

The Coal Mining Industry (Pneumoconiosis) Compensation Scheme issued under the 1943 Act, came into force on July I, 1943, and applied to underground workmen and certain surface workers in coal mines employed on or after July I, 1943 . The Pneumoconiosis (Benefit) Scheme, 1943, made provision for the payment of a benefit in the form of a weekly payment of I $_{5}$ s. to workmen employed in or about any coal mine after October 22, I934, but not after June 30, 1943. This helped a number of cases who could not claim under the compensation schemes. The benefit was limited to those certified to be totally disabled and there was also a death benefit payable to dependants.

The restriction that benefit shall not be payable in any case where the total disablement of the workmen, or his death, if he died without having been certified in life, took place five years after July I, 1943, was removed by a non-statutory Supplementary Benefit Scheme arranged with the National Coal Board in 1948.

\section{Haematite Miners}

These miners were provided for by an amendment to the Various Industries (Silicosis) Scheme, in January, 1935, which added to the processes that of " any operation underground in haematite iron ore mines.' Ten years before, Cronin had investigated the dust risk in the Cumberland iron ore mines but at that time X-ray facilities were poor. Several studies were made after that one of note by Stewart and Faulds (1934), in which they established that silicosis was found in these miners, and although it might be modified by presence of the iron ore in the lungs it seemed to be of a serious type.

\section{Slate Workers}

These were not specifically mentioned in the scheme until 1939, when ' any operation under-.ground in slate mines' was added. The risk $\overrightarrow{\vec{F}}$ of workers engaged in the dressing and splitting? of slate was investigated by Sutherland and등 and Bryson (1930), when those engaged as $\frac{\bar{\omega}}{\omega}$ millmen were found to be specially affected. $\overrightarrow{\mathrm{D}}$ The dangerous conditions in the slate mining in- $\varrho$ dustry were brought to light by Davies (1939) and कै led to action being taken for slate miners, but it $\overrightarrow{0}$ was not until 1946 that splitters and dressers $\overrightarrow{-}$ received recognition.

\section{Coal Trimmers}

Attention had been called to the effects of the dust in holds of ships loading coal on the lungs of $\mathrm{N}$ the trimmers by members of the Welsh National 0 Memorial Association in 1926. Later an enquiry was carried out by the Medical Research Council, ${ }^{\circ}$ when Keating and Thomas examined a number of trimmers at Swansea and Cardiff. Further in: vestigations were also carried out by Hart and Aslett as part of their larger investigation. TH pathological aspect was studied in detail by Professor Gough who found that the condition was similar to that found in coal miners. Probab\& national rather than medical reasons delaye matters, but finally a Shipping Industry (Pneume: coniosis) Comnensation Scheme, 1946, broug居 them in line.

\section{Iron Casters}

In the moulding of iron castings the use of $\frac{\mathrm{Q}}{\square}$ parting powder to facilitate the removal of the $\overrightarrow{\vec{F}}$ casting from the mould was found to lead to the $\frac{0}{3}$ development of silicosis. This was because the parting powder used very often contained silica or was a fine powder of silica itself. As proof of the effect of this powder had been produced, 3 . the occupation of the "moulding of iron castings $\frac{}{\sigma}$ with the use of siliceous materials in a facing powder or a parting powder' was dealt with in the $\delta$ Various Industries (Silicosis) Amendment Scheme, 1946.

\section{The Manufacture of Scouring Powders}

This, among other processes, was included under the clause :- Breaking, crushing, grinding, $\infty$ sieving, mixing or packing of silica rock, or of $N$ dried quartzose sand or any dry deposit or dry $N_{\omega}^{N}$ residue of silica or any admixture containing such materials.'

Scouring powders received rather an unfavour- $\frac{0}{\Phi}$ able publicity owing to the publication of a paper $\stackrel{\oplus}{+}$ 
by McDonald et al. (1930) which described cases occurring amongst girls engaged in packing a scouring powder. Such powders were composed mainly of a fine silica powder and soap powder. It was suggested that the alkaline soap made the silica specially soluble; this probably was pushing the silica solubility theory to excess since the powder was fine enough to be dangerous when inhaled and the girls were apparently also subjected to exposure to tuberculosis infection at the same time.

\section{Byssinosis}

This is the disabling condition resulting from long-continued exposure to the dust of cotton in cardrooms, blowing rooms and cotton rooms in factories in the cotton spinning industry. A departmental committee reported on the subject in 1932, but as the condition differed from the pneumoconiosis in many respects it had to be treated differently. The disabling condition of the lungs is not a fibrosis but a combination of emphysema and bronchitis which is difficult to diagnose at an early stage and is not uncommon in the general population of Lancashire. To get over these difficulties compensation was made payable only to men who had been employed for 20 years in the cotton rooms, blowing rooms and cardrooms in mills where the spinning of raw cotton was carried on, and who were totally disabled. Two schemes containing these provisions were issued under a special Act. One was Byssinosis (Workmen's Compensation) Schemes, 194I, and the other the Byssinosis (Benefit) Scheme, I94I; the latter now gives a benefit of 20 . a week to workers who were not entitled to claim under the compensation scheme because they had not been employed after the specified date, May I, r94I.

\section{Prevention}

The historical account just given shows how knowledge of the diseases caused by dust has been slowly built up. This information has been applied not only in providing compensation but in the application of preventive measures. All three hang together, knowledge of a risk, prevention of its effects, compensation to sufferers. Usually, before the introduction of any compensation scheme, regulations as to prevention were issued by the Factory Department or Mines Department. The Factory Act, 1937, specifically mentions preventive measures against dust in Section 47 .

Meanwhile, the Ministry of Fuel and Power has pushed on with the use of preventive measures particularly in the coal-mines of South Wales. Water infusion, floor consolidation and water spraying are enforced. The National Coal Board $\stackrel{0}{0}$ have arranged for inspections and for dust counts, and have laid down limits of dusty conditions as a을 standard to be aimed at.

The National Insurance (Industrial Injuries)
Act, 1946

The Act, which came into force on July 5 , 1948, does more than replace the Workmen's Compensation Acts; it introduces a new outlook on injury sustained at work. A social service in $\widetilde{\mathbb{\Phi}}$ the form of an insurance is instituted; benefit

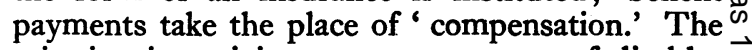
criterion in arriving at an assessment of disable- $\overrightarrow{0}$ ment benefit is no longer loss of earnings. The $\overrightarrow{\vec{H}}$ criterion is now loss of physical or mental faculty. $\stackrel{\sim}{\sigma}$

In the case of pneumoconiosis the injury to the $\bar{D}$ lungs may lead to loss of faculty in the form of 3 shortness of breath, and other symptoms. This i imposes disabilities at work or play as, for example, ir inability to climb stairs or to walk quickly. The sum of these disabilities makes up the disablement.

\section{Definition of Pneumoconiosis}

Pneumoconiosis is defined in the Nationgl Insurance (Industrial Injuries) Act, Section 57 (\$尺) as:- 'Fibrosis of the lungs due to silica dusf asbestos dust or other dust, and includes the condition of the lungs known as dust reticulationo

Pneumoconiosis is thus used as a term to cover the different types of dust disease of the lungs and the words silicosis and asbestosis are droppef. The narrow radiological standard of diagnosis of silicosis (i.e. nodulation) is modified and to some extent there is a broadening of the basis of diagnosis since in some exposures a reticulation $\stackrel{\unrhd}{\circledR}$ has been observed to appear before a definite $\overrightarrow{\vec{*}}$ nodulation is recognizable. The 'condition $\frac{0}{3}$ known as dust fibrosis' may, or may not, be a fibrosis according to whether one regards a

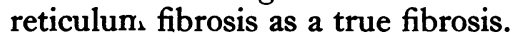

Byssinosis is not included in the pneumoconiosis but is treated as a.separate entity. It is not defined in the Act but by inference it means a chronic lung condition causing severe disablement $\delta$ in workers in cotton rooms, cardrooms and blowing rooms in cotton mills.

\section{Occupations}

The processes and occupations covered are listed in Part 2 of the First Schedule of the National Insurance (Industrial Injuries) (Pre- $N$ scribed Diseases) Regulations, 1948, S.I. No. I37I. స్ These regulations should be consulted for certain definitions. The occupations listed are :-

I. Any occupation involving-

(a) the mining, quarrying or working of silica 
rock or the working of dried quartzose sand or any dry deposit or dry residue of silica or any dry admixture containing such materials (including any occupation in which any of the aforesaid operations are carried out incidentally to the mining or quarrying of other minerals or to the manufacture of articles containing crushed or ground silica rock);

(b) the handling of any of the materials specified in the foregoing sub-paragraph in or incidental to any of the operations mentioned therein, or substantial exposure to the dust arising from such operations.

2. Any occupation involving the breaking, crushing or grinding of flint or the working or handling of broken, crushed or ground flint or materials containing such flint, or substantial exposure to the dust arising from any of such operations.

3. Any occupation involving sand blasting by means of compressed air with the use of quartzose sand or crushed silica rock or flint, or substantial exposure to the dust arising from such sand blasting.

4. Any occupation involving-

(a) the freeing of steel castings from adherent siliceous substance;

(b) the blasting of metal castings to free them from adherent siliceous substance by means of any abrasive, by a blast of compressed air, by steam or by a wheel;

(c) the moulding of iron castings with the use of siliceous materials as a facing powder or parting powder;

(d) substantial exposure to the dust arising from any of the foregoing operations.

5. Any occupation in or incidental to the manufacture of china or earthenware (including sanitary earthenware, electrical earthenware and earthenware tiles), and any occupation involving substantial exposure to the dust arising therefrom.

6. Any occupation involving the grinding of mineral graphite, or substantial exposure to the dust arising from such grinding.

7. Any occupation involving the dressing of granite or any igneous rock by masons or the crushing of such materials, or substantial exposure to the dust arising from such operations.

8. Any occupation involving the use, or preparation for use, of a grindstone, or substantial exposure to the dust arising therefrom.

9. Any occupation involving-

(a) the working or handling of asbestos or any admixture of asbestos;

(b) the manufacture or repair of asbestos textiles or other articles containing or composed of asbestos;

(c) the cleaning of any machinery or plant used in any of the foregoing operations and of any chambers, fixtures and appliances for the collection of asbestos dust;

(d) substantial exposure to the dust arising from any of the foregoing operations.

ro. Any occupation involving-

(a) work underground in any coal, tin, slate or haematite iron ore mine;

(b) the working, or handling above ground at any coal or tin mine of any minerals extracted therefrom, or any operation incidental thereto;

(c) the trimming of coal in any ship, barge, or lighter, or in any dock or harbour or at any wharf or quay;

(d) the sawing, splitting or dressing of slate, or any operation incidental thereto.

All the processes covered by the Workmen's Compensation Schemes are included but by the wording the scope of the list is increased. In addition, one process not covered by the Workmen's Compensation Scheme is included, namely, the grinding of graphite. This was the result of the reports of the effects of graphite dust by Dunner (1945) and by Harding (1949).

Many workers who have not been employed in the processes in the list after July 5, 1948, may have formerly been employed in one of the occupa $\frac{0}{\mathbb{D}} \mathbb{\Phi}$ tions under the Silicosis Schemes. If they hav $\mathbb{D}$

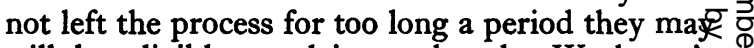
still be eligible to claim under the Workmen's Compensation Acts. For some time there wi迹 be a diminishing number of such claims. If addition, death claims from those who have been in receipt of compensation during life under the old Acts are still made under those Acts.

\section{Disablement Benefit}

In pneumoconiosis and byssinosis there is no injury benefit. The award is for disablement benefit from the beginning. The scale of assessments is similar to that paid in accident cases with the exception that instead of a gratuity for less than 20 per cent. assessment, there is an assessment of ro per cent. The basic benefit rates are as follows:-

$$
\begin{aligned}
& \text { Per cent. } \\
& \begin{array}{llllll}
\text { Up to } 5 & \ldots & \ldots & \ldots & \ldots & \text { s. Nil }
\end{array}
\end{aligned}
$$

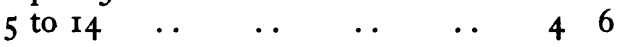

$$
\begin{aligned}
& \begin{array}{llllllll}
20 & \ldots & \ldots & \ldots & \ldots & \ldots & 9 & 0
\end{array} \\
& 30 \ldots \quad \text {.. } \\
& \begin{array}{llllllll}
40 & \ldots & \ldots & \ldots & \ldots & \ldots & 18 & 0
\end{array}
\end{aligned}
$$

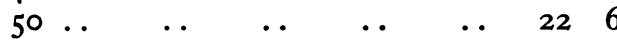

$$
\begin{aligned}
& \begin{array}{llllllll}
60 & \ldots & \ldots & \ldots & \ldots & \ldots & 27 & 0
\end{array} \\
& \begin{array}{llllllll}
70 & \ldots & \ldots & \ldots & \ldots & \ldots & 31 & 6
\end{array}
\end{aligned}
$$

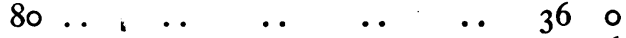

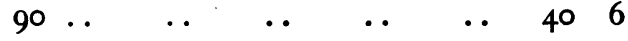

$$
\begin{aligned}
& \text { I00 } \ldots \quad \ldots \quad \ldots \quad \ldots \quad \ldots \quad \ldots \quad \ldots 450
\end{aligned}
$$$$
\text { Per week }
$$ 
The assessment is made to the nearest ten, giving I I grades contrasting with the four (ordinary work, moderately heavy work, light work and total disablement) of the Workmen's Compensation Act where loss of earning power was the sole consideration. Only those whose assessment of roo per cent. are considered final; the others are provisional and for a limited period, usually a year. Beneficiaries are therefore examined and reassessed at intervals and their progress is watched; this was not possible under the old schemes and not only was much information lost as to progression but the compensated worker was deprived of any future special advice as to his condition.

In byssinosis, benefit is payable now not only to those who are totally disabled, as formerly, but to those whose disablement is assessed at not less than 50 per cent. Women are now for the first time eligible to claim benefit on account of byssinosis.

It should be mentioned here that those in receipt of benefit for pneumoconiosis or byssinosis may be eligible for such additional benefits as Constant Attendance Allowance, Unemployability Supplement or Special Hardship Allowance so that the scale already shown does not necessarily represent the total awarded.

\section{Examinations}

The provisions as to examinations are given in the National Insurance (Industrial Injuries) (Pre-气 scribed Diseases) Regulations. Medical boards 3 of two or more medical officers are drawn from $\stackrel{\$}{\complement}$ the Pneumoconiosis Medical Panels which are $\subseteq$ the successors of the Silicosis Medical Board. $\overrightarrow{\vec{F}}$ They are placed at the following centres (Swansea, $\stackrel{?}{0}$ Cardiff, Stoke, Sheffield, Manchester, London and Edinburgh) and still act in Workmen's Com- $\frac{\bar{\sigma}}{\bar{c}}$ pensation Act cases remaining over from pre July $\vec{\nabla}$ 5, r948. The Pneumoconiosis Medical Panels also 응 carry out the initial and periodical examinations in $\%$ the same processes as before.

Application for benefit in respect of pneumoconiosis and byssinosis has to be made at the $\vec{\omega}$ local National Insurance Office, and after pre- $\frac{o}{0}$ liminary enquiries the case is passed to the $\frac{0}{3}$ Penumoconiosis Medical Panels. An X-ray examination of the chest is made and if no trace of or the disease or of tuberculosis is found the claim to benefit would normally be rejected. If the claimant appeals against the decision or if there ${ }_{0}$ is evidence of disease in the X-ray, the claimant 0 is examined by a medical board. The board" decision on the diagnosis question is final. diagnosed cases the board proceeds to assess the disablement, and if provisional, to state the duratı $\Phi$ of the assessment. They also advise the beneficia as to his future employment.

\section{BIBLIOGRAPHY}

COLLIS, E. L. (1915), 'Industrial Pneumoconiosis.' Milroy Lectures. H.M. Stationery Office.

COOKE, W. E. (1924), Brit. Med. F., II, 147.

DAVIES, T. W. (1939), Tubercle, 20, 543.

DUNNER, L. (1945), Brit. F. Rad., 18, 33

- First Report of the Departmental Committee on Compensation for Silicosis ' (Dealing with the Refractories Industries (Silicosis) Scheme, rorg) (r924), H.M. Stationery Office.

' General Report of the South African Miners Phthisis Prevention Committee' (r916).

GOUGH, J. (1948), f. Path. and Bact., 51, 277:

HALDANE, J. B., MARTIN and THOMAS (1904), ' Report on the Health of Cornish Miners.' 'H.M. Stationery Office.

HARDING, H. E., and OLIVER, G. B. (1949), Brit. Med. F., 6, 9I.

HART, P. D'ARCY, ASLETT, E. A., BELT, T. H., and FERRIS, A. A. (1942), 'Chronic Pulmonary Diseases in South Wales Coal Miners.' Special Report Series, M.R.C., No. 243. H.M. Stationery/Office.

MACKLIN, E. L., and MIDDLETON, E. L. (1923), ' Report on the Grinding of Metals and Cleaning of Castings.' H.M. Stationery Office.

MCDONALD, STUART (1927), Brit. Med. F., 11, 1025.
MCDONALD, G., et al. (1930), Lancet, Ir, 846.

MEREWETHER, E. R. A. (1936), 'Risk of Silicosis in Sandblasters,' Tubercle.

MEREWETHER, E. R. A., and PRICE, C. W. (1930), ' Report on the Effects of Asbestos Dust on the Lungs.' H.M. Stationery Office.

- Report of Departmental Committee on Compensation for Industrial Diseases' (1907), H.M. Stationery Office.

'Report of the Departmental Committee on Compensation for Silicosis' (Dealing with the Pottery Industry) (1928), H.M. Stationery Office.

' Report of the Departmental Committee on Dust in Cardrooms in the Cotton Industry ' (1932), H.M. Stationery Office.

SEILER, H. E. (1928), Brit. Med. F., 11, 982.

STEWART, M. J., and FAULDS, J. S. (1934), fournal Path. and

Bact., 39, 233.
SUMMONS, W. (1907), 'Miners Phthisis at Bendigo,' Stillwell
and Company, Melbourne. and Company, Melbourne.

SUTHERLAND, C. L., and BRYSON, S. (1926), 'Report on the Incidence of Silicosis in the Pottery Industry.' 'H.M. Stationery Office.

SUTHERLAND, C. L., and BRYSON, S. (1930), 'Disease of the Lungs in the Slate Industry.' H.M. Stationery Office.

TATTERSALL, N. (1926), fournal of Industrial Hygiene, 7, 466 